\title{
Rasio lebar mesiodistal gigi Bolton pada geligi berjejal dan geligi normal
}

\author{
Susilowati,* Meryl Dekaria** \\ * Bagian Ortodonsia \\ ** Mahasiswi tingkat kepaniteraan \\ Fakultas Kedokteran Gigi Universitas Hasanuddin
}

\begin{abstract}
The orthodontic "finishing" phase is recognized for the many details to accomplish an excellent result. A high percentage of finishing-phase difficulties arise because of tooth size imbalance that could have been considered during the initial diagnosis and treatment planning. The aim of this study was to determine whether the Bolton's analysis applies for the crowded and non crowded dentitions. This study involved 60 subjects (30 crowded and 30 non-crowded; 29 males and 31 females). Criteria for sample selection comprised absence of interproximal caries/filling, no residual crown-bridge restoration, no tooth deformity, aged over 17 years, never undergone orthodontic treatment, and the presence of teeth from right first molar through left first molar, both upper and lower. Tooth size measurements were performed on study models. The statistical analysis used were descriptive and t-test. The results of the study were as follows: the mesiodistal tooth widths on males were bigger that those on females, the mesiodistal tooth widths on crowded group were bigger than those on normal group but the difference was insignificant statistically ( $>0.05$ ); anterior ratio in crowded group was smaller that that in normal group; overall ratio in crowded group was bigger than that in normal group but the difference was insignificant $(\mathrm{p}>0.05)$. Anterior ratio of the two groups was bigger than Anterior Bolton Mean, it means that the discrepancy was present on the lower arch. Overall ratio of the two groups was smaller than Overall Bolton Mean, it means that the discrepancy was present on the upper arch.
\end{abstract}

Key words: Bolton ratio, crowded, non-crowded 


\begin{abstract}
ABSTRAK
Tahap penyelesaian kasus ortodontik ditengarai memerlukan banyak detail untuk mendapatkan hasil yang sempurna. Tingginya persentase dari kesulitan tahap penyelesaian diakibatkan karena ketidakseimbangan ukuran gigi yang seharusnya telah ditemukan dan dipertimbangkan selama diagnosis awal dan perencanaan perawatan. Tujuan dari penelitian ini ialah untuk mengetahui penerapan analisis Bolton pada geligi berjejal dan normal. Penelitian ini melibatkan 60 subyek (30 geligi berjejal dan 30 geligi normal, 29 laki-laki dan 31 perempuan). Sampel harus memenuhi kriteria sebagai berikut: bebas dari karies/tambalan interproksimal, usia di atas 17 tahun, belum pernah dirawat ortodontik, mempunyai gigi lengkap dari molar pertama kiri sampai dengan molar pertama kanan baik pada RA maupun RB. Pengukuran lebar mesiodistal gigi dilakukan pada model. Analisis statistik yang dipakai adalah analisis deskriptif dan uji-t. Hasil penelitian ini ialah lebar mesiodistal gigi laki-laki lebih besar dibanding gigi perempuan untuk kedua kelompok; rerata lebar mesiodistal pada kelompok geligi berjejal lebih besar dibanding kelompok geligi normal, tetapi tidak bermakna secara statistik (p>0,05); Rasio Bolton Anterior pada geligi berjejal lebih kecil dari geligi normal, sedang Rasio Bolton Total pada geligi berjejal lebih besar dari geligi normal, tetapi perbedaan ini tidak bermakna ( $>>0,05)$. Rasio anterior pada kedua kelompok lebih besar dari Konstanta Bolton, berarti terjadi diskrepansi pada rahang bawah. Rasio total pada kedua kelompok lebih kecil dari Konstanta Bolton, berarti terjadi diskrepansi pada rahang atas.
\end{abstract}

Kata kunci: rasio Bolton, geligi berjejal, geligi normal

Koresponden: Susilowati, Bagian Ortodonsia, Fakultas Kedokteran Gigi Universitas Hasanuddin, J1. Kandea No.5 Makassar, Indonesia.

\section{PENDAHULUAN}

Perawatan ortodontik bertujuan untuk mendapatkan oklusi yang sehat secara fungsional maupun estetik. Kesuksesan perawatan ini didasarkan pada diagnosis dan rencana perawatan yang komprehensif.
Beberapa faktor yang fundamental dalam menegakkan diagnosis adalah kondisi ruang, ukuran dan bentuk gigi serta rahang, tumpang gigit, jarak gigit serta diskrepansi lengkung gigi.1 Kemungkinan yang paling besar berpengaruh terhadap oklusi adalah 
variasi besar dan bentuk gigi. Ukuran baku yang dipergunakan berasal dari sampel dari masyarakat tertentu, tidak cukup akurat untuk dipergunakan pada masyarakat lainnya oleh karena terdapat perbedaan ukuran antara suku yang satu dengan lainnya. Ukuran gigi juga dipengaruhi oleh jenis kelamin dan faktor genetik, sedangkan faktor lingkungan walaupun sedikit pengaruhnya tetap harus diperhatikan.2

Keberjejalan (crowded) dan ketidakteraturan gigi masih tetap merupakan dua komponen maloklusi yang paling sering dialami pasien kedokteran gigi, baik anakanak maupun orang dewasa. Penatalaksanaan masalah ruang terus berperan penting dalam praktek kedokteran gigi. Bidang ini juga merupakan bidang utama tempat berinteraksinya pemberi layanan kesehatan pertama dan spesialis. 3

Para ortodontis telah menggunakan beberapa metode untuk mendeteksi diskrepansi ukuran gigi antara rahang pada pasien yang akan menjalani perawatan orthodontik, misalnya diagnostic set-up dari Kesling, rasio interfossa kanina dengan lebar total gigi atas dari Howes, dan koefisien anterior dari Neff. Tetapi yang paling sering digunakan adalah analisis dari Bolton. Hal ini dapat ditentukan dengan menggunakan rasio lebar gigi rahang bawah $(\mathrm{RB})$ terhadap rahang atas (RA) yang kemudian dibandingkan dengan nilai Konstanta Bolton sehingga dapat disimpulkan lengkung gigi mana yang menyebabkan diskrepansi.4 Bolton mengembangkan rasio anterior dan rasio total berdasar pada 55 pasien Kelas I yang sempurna. Meskipun analisis Bolton telah terbukti sangat berguna dalam klinik untuk membantu ortodontis menangani kasus diskrepansi yang parah, namun masih memiliki keterbatasan. Pertama, estimasi Bolton untuk variasi adalah kurang karena sampel yang dipakai adalah Kelas I yang sempurna. Kedua, yang mungkin lebih penting, komposisi populasi dan jenis kelamin tidak spesifik yang potensial menyebabkan bias.5,10

Walaupun perbedaan antara lebar mesiodistal gigi pada geligi berjejal dan geligi normal telah dilaporkan dalam beberapa penelitian, hanya sedikit penelitian yang menganalisis lebar mesiodistal gigi secara kolektif. Lundstrom6 tidak menemukan perbedaan antara rasio lebar gigi yang diajukannya dengan besarnya keberjejalan, namun ukuran sampel geligi normal pada penelitian ini kecil. Nodervall7 dan kawan-kawan hanya meneliti rasio lebar gigi anterior. Oleh karena keberjejalan gigi dihubungkan dengan lebar gigi yang lebih besar, ada 
kemungkinan bahwa ketidakseimbangan hubungan lebar gigi antar-lengkung pada daerah lengkung posterior juga dapat mempengaruhi adanya keberjejalan gigi. Diskrepansi lebar gigi dapat mempengaruhi keberhasilan penyelesaian kasus ortodontik.8

Penelitian ini dirancang untuk mengevaluasi rasio lebar gigi pada geligi berjejal dan geligi normal serta menjelaskan implikasi klinis dari kemungkinan perbedaan-perbedaannya.

Tujuan dari penelitian ini ialah untuk mengetahui perbedaan (1) lebar gigi lakilaki dan perempuan, (2) lebar mesiodistal gigi yang berjejal dengan yang normal, (3) antara rasio anterior dan rasio total pada geligi yang berjejal dengan yang normal, dan (4) diskrepansi pada kedua lengkung dengan membandingkan rasio penelitian dengan konstanta Bolton.

\section{BAHAN DAN METODE}

Penelitian ini merupakan penelitian observasional analitik dengan pengambilan sampel secara purposif pada mahasiswa Fakultas Kedokteran Gigi Universitas Hasanuddin. Sampel yang berjumlah 60 orang memenuhi kriteria sebagai berikut, usia minimal 17 tahun, mempunyai gigi lengkap dari molar pertama kiri sampai dengan molar pertama kanan pada RA dan $\mathrm{RB}$, tidak ada karies, atrisi dan restorasi pada permukaan proksimal atau anomali lain dalam jumlah, bentuk dan ukuran yang ekstrim, tidak pernah/sedang menjalani perawatan ortodontik. Sebanyak 30 sampel mempunyai susunan gigi berjejal, sedang 30 lainnya normal. Pada subyek dilakukan pencetakan lengkung giginya dengan bahan Alginat, kemudian cetakannya dicor dengan gips keras. Pada model studi ini dilakukan pengukuran lebar mesiodistal gigi atas dan bawah dari molar pertama kiri sampai dengan molar pertama kanan.menggunakan kaliper geser.

Analisis Bolton Total didapatkan dengan membagi jumlah gigi RB dengan RA melalui perhitungan jumlah ukuran 6 gigi anterior, premolar pertama dan kedua kiri-kanan serta molar pertama kiri-kanan. Selanjutnya dibandingkan dengan nilai konstanta Bolton 91,3\%. Hasil hitungan, jika rasio lebih besar dari nilai tersebut, diskrepansi diduga pada lengkung RB, sedangkan kalau rasio yang dihasilkan kurang dari nilai tersebut maka diskrepansi diduga pada lengkung RA.13

Analisis Bolton Anterior didapatkan dengan menjumlahkan 6 gigi anterior bawah dibagi dengan 6 gigi anterior atas. Jika hasil hitungan melebihi nilai konstanta Bolton 
$77,2 \%$ maka diduga diskrepansi pada lengkung $\mathrm{RB}$ dan apabila rasio yang dihasilkan kurang dari $77,2 \%$, maka diskrepansi diduga pada lengkung RA.13

Data yang diperoleh diolah dengan komputer menggunakan program SPSS dan dianalisis secara deskriptif dan diuji secara statistik dengan uji-t. Rasio anterior dan total dikelompokkan nilai reratanya dibandingkan dengan konstanta Bolton.

\section{HASIL PENELITIAN}

Pada tabel 1, tampak rerata geligi berjejal pada RA laki-laki $(84,2 \mathrm{~mm})$ lebih besar dibanding rerata pada RA perempuan (78,99 mm). Rerata pada RB laki-laki $(72,87$ $\mathrm{mm})$ lebih kecil dari rerata pada RB perempuan $(77,02 \mathrm{~mm})$. Tampak pula rerata geligi normal pada RA laki-laki RA (77,9 $\mathrm{mm}$ ) lebih besar dari rerata pada RA perempuan $(75,36 \mathrm{~mm})$. Rerata pada $\mathrm{RB}$ laki-laki $(67,81 \mathrm{~mm})$ lebih besar dari pada rerata pada $\mathrm{RB}$ perempuan $(65,38 \mathrm{~mm})$.

Tabel 1. Lebar mesiodistal gigi kelompok geligi berjejal dan normal pada laki-laki dan perempuan.

\begin{tabular}{llllllll}
\hline Geligi & Jenis & Rahang & $\begin{array}{l}\mathrm{n} \\
(\mathrm{mm})\end{array}$ & $\begin{array}{l}\text { Min } \\
(\mathrm{mm})\end{array}$ & $\begin{array}{l}\text { Maks } \\
(\mathrm{mm})\end{array}$ & Rerata & SD \\
\hline \multirow{3}{*}{ Kelamin } & Laki-laki & Atas & 15 & 74,0 & 89,0 & 84,20 & 0 \\
& & Bawah & 15 & 66,0 & 77,5 & 72,87 & 2,81 \\
\cline { 2 - 7 } & \multirow{2}{*}{ Perempuan } & Atas & 15 & 72,8 & 85,0 & 78,99 & 3,96 \\
& & Bawah & 15 & 65,5 & 77,5 & 77,02 & 3,74 \\
\hline \multirow{3}{*}{ Normal } & \multirow{2}{*}{ Laki-laki } & atas & 15 & 72,5 & 84,0 & 77,90 & 6 \\
& & Bawah & 15 & 52.0 & 73,0 & 67,81 & 3,37 \\
\cline { 2 - 7 } & \multirow{2}{*}{ Perempuan } & Atas & 15 & 68,9 & 84,0 & 75,36 & 4,18 \\
& & Bawah & 15 & 60,0 & 73,7 & 65,38 & 3,68 \\
\hline
\end{tabular}

Kererangan : n:besar sampel ; Min:minimal ; Maks:maksimal ; SD:standar deviasi 
Tabel 2. Rerata lebar mesiodistal gigi molar pertama ke molar pertama pada kelompok geligi berjejal dan geligi normal (uji-t).

\begin{tabular}{llllll}
\hline Rahang & Kelompok & $\mathrm{n}$ & Rerata $(\mathrm{mm})$ & SD & Signifikansi \\
\hline \multirow{2}{*}{ Atas } & Berjejal & 30 & 81,00 & 4,68 & \\
& Normal & 30 & 76,57 & 3,86 & 0,19 \\
\hline \multirow{2}{*}{ Bawah } & Berjejal & 30 & 71,44 & 3,56 & \\
& Normal & 30 & 66,51 & 3,69 & 0,77 \\
\hline
\end{tabular}

Kererangan : n:besar sampel ; SD:standar deviasi

Tabel 3. Rerata rasio Bolton pada kelompok geligi berjejal dan geligi normal (uji-t).

\begin{tabular}{lllll}
\hline Rasio Bolton & Kelompok & Nilai & SD & Signifikansi \\
\hline \multirow{2}{*}{ Rasio Anterior } & Berjejal & 79,26 & 3,15 & \\
& Normal & 79,81 & 3,83 & 0,34 \\
\hline \multirow{2}{*}{ Rasio Total } & Berjejal & 71,44 & 3,55 & \\
& Normal & 66,51 & 3,72 & 0,10 \\
\hline
\end{tabular}

Kererangan : SD:standar deviasi

Sedangkan pada tabel 2 ditunjukkan bahwa pada RA, untuk kelompok geligi berjejal rerata lebar mesiodistal gigi geligi lebih besar dari pada rerata pada kelompok normal. Pada RB, untuk kelompok geligi berjejal rerata lebar mesiodistal gigi geligi lebih besar dari pada rerata pada kelompok normal. Baik pada RA maupun RB secara statistik tidak terdapat berbeda bermakna $(\mathrm{p}>0,05)$.

Pada tabel 3, tampak bahwa rasio anterior pada kelompok geligi berjejal lebih kecil dari kelompok geligi normal; sedangkan rasio total pada kelompok geligi berjejal lebih besar dari kelompok geligi normal. Meskipun demikian, keduanya tidak berbeda bermakna $(\mathrm{p}>0,05)$.

\section{PEMBAHASAN}

Pada tabel 1 terlihat bahwa rerata lebar mesiodistal gigi geligi laki-laki lebih besar dari pada perempuan. Hal ini sesuai dengan penelitian Potter7 dan Araujo.8,12 Walaupun rerata lebar mesiodistal berbeda, tetapi tidak selalu menghasilkan rasio yang berbeda pula, karena tergantung dari 
pembilang dan penyebutnya. Maka dari itu, rasio Bolton tidak membedakan jenis kelamin. Bolton yakin bahwa rasio total yang diperoleh, mewakili rasio "ideal" yang dapat digunakan pada setiap jenis oklusi. Oklusi yang berlainan dengan rasio ideal ini berarti memiliki kelainan ukuran (diskrepansi) gigi pada satu atau kedua lengkung rahang.

Pada tabel 2 terlihat bahwa rerata lebar mesiodistal gigi pada kelompok geligi berjejal pada RA maupun RB relatif lebih besar dibanding kelompok normal, tetapi secara statistik tidak berbeda bermakna. Salah satu penyebab gigi berjejal adalah ukuran gigi geligi relatif lebih besar dibanding tulang basal/rahangnya. Sejumlah faktor yang berperan dalam variasi ukuran gigi adalah ras, jenis kelamin, keturunan, dan lingkungan (nutrisi, penyakit, dan iklim).9,13 Hasil yang tidak signifikan dalam penelitian ini disebabkan karena kemungkinan penyebab keberjejalan di sini bukan karena lebar mesiodistalnya tetapi karena ukuran rahang yang relatif lebih kecil. Seperti diketahui bahwa keberjejalan bisa disebabkan karena ukuran gigi besar tetapi ukuran rahangnya normal atau ukuran gigi geligi normal tetapi ukuran rahangnya kecil.
Pada tabel 3 terlihat bahwa rasio Bolton anterior pada kelompok geligi berjejal menunjukkan perbedaan yang tidak bermakna dengan kelompok normal(P0,05). Rasio anterior untuk kelompok geligi berjejal sebesar 79,26, berarti lebih besar dari Konstanta Bolton Anterior (77,2). Artinya, terjadi diskrepansi yang penyebabnya adalah RB. Pada kelompok geligi normal, rasio anterior diperoleh 79,81 yang juga lebih besar dari Konstanta Bolton Anterior. Jadi penyebab diskrepansinya adalah RB.

Rasio Bolton Total untuk kelompok geligi berjejal juga menunjukkan perbedaan yang tidak bermakna dengan kelompok normal (P0,05). Rasio total diperoleh 71,44 untuk kelompok geligi berjejal dan 66,51 untuk kelompok geligi normal. Hal ini berarti lebih kecil dari Konstanta Bolton Total (91,3), artinya terjadi diskrepansi yang disebabkan oleh RA.

Terlihat dari tabel di atas bahwa meskipun gigi geligi tidak tidak berjejal atau normal, bisa terjadi diskrepansi. Implikasi klinisnya yaitu bahwa jenis maloklusi bukan hanya keberjejalan gigi, bisa saja retrusi, protrusi, diastema dan lain-lain. Intinya, apabila terjadi diskrepansi baik pada geligi berjejal maupun normal, perawatan yang 
akan dilakukan ialah pada lengkung yang mengalami diskrepansi.

\section{SIMPULAN}

Berdasarkan hasil penelitian ini, disimpulkan bahwa lebar mesiodistal gigi geligi laki-laki lebih besar dibanding lebar mesiodistal gigi geligi perempuan baik pada kelompok geligi berjejal maupun kelompok geligi normal. Sedangkan rerata lebar mesiodistal gigi geligi pada kelompok geligi berjejal lebih besar dari kelompok geligi normal, tetapi secara statistik perbedaan ini tidak bermakna.

Rasio Bolton Anterior pada kelompok geligi berjejal lebih kecil dari kelompok normal, tetapi perbedaan ini secara statistik tidak bermakna. Sedangkan Rasio Bolton Total pada kelompok geligi berjejal lebih besar dari kelompok normal, tetapi tidak bermakna secara statistik.

Rasio anterior pada kedua kelompok lebih besar dari Konstanta Bolton Anterior, artinya terjadi diskrepansi pada RB. Sedangkan rasio total pada kedua kelompok lebih kecil dari Konstanta Bolton Total, artinya terjadi diskrepansi pada RA.

\section{SARAN}

Untuk menambah validitas dari penelitian sejenis ini, jumlah sampel perlu diperbesar. Di samping itu, dalam melakukan rencana perawatan ortodontik, sebaiknya analisis Bolton didukung oleh metode analisis yang lain, misalnya analisis dari Howes, Pont dan Kesling.

\section{Ucapan terima kasih}

Penelitian ini dilakukan dengan bantuan dana Hibah Penelitian PHK A2 FKG Unhas 2006

\section{DAFTAR PUSTAKA}

1. Sony Swasono, Susilowati. Validitas rasio Bolton pada orang Bugis dan Toraja. J Medika Nusantara 2003; 14 (1).

2. Budiman PJ, Yashadana EDD, Sadoso SD, Masbirin PL. Hubungan rasio anterior dengan overjet dan overbite pada perawatan orthodontik. J Ked Gigi UI 1997; 4(3):303-7.

3. Ngan P, Alkire RG, Fields H. Management of space problems in the primary mixed dentition. J Am Dent Assoc 1999; 130:1330-9.

4. Stifter J. A study of Pont's, Howes', Rees', Neff's, and Bolton's analysis on class I adult dentitions. Angle Orthodontist 1985; 28: 215-25.

5. Zibermann O. Evaluation of the validity of tooth size and arch width 
measurement using conventional and three-dimensional virtual orthodontic

model. Angle Orthodontist 2002; 73

(3): 301-6. 